IdeAs

Idées d'Amériques

12 | 2018

Le tourisme dans les Amériques

\title{
Antoine Faure, Franck Gaudichaud, María Cosette Godoy H., Fabiola Miranda P., René Jara (dir.), Chili actuel: gouverner et résister dans une société néolibérale
}

Paris, L'Harmattan, 2016, 280 p.

Stéphane Boisard

\section{OpenEdition}

Journals

Édition électronique

URL : https://journals.openedition.org/ideas/4457

DOI : $10.4000 /$ ideas.4457

ISSN : 1950-570

Éditeur

Institut des Amériques

\section{Référence électronique}

Stéphane Boisard, « Antoine Faure, Franck Gaudichaud, María Cosette Godoy H., Fabiola Miranda P.

René Jara (dir.), Chili actuel : gouverner et résister dans une société néolibérale », IdeAs [En ligne], 12 |

2018, mis en ligne le 16 novembre 2018, consulté le 20 octobre 2022. URL : http://

journals.openedition.org/ideas/4457 ; DOI : https://doi.org/10.4000/ideas.4457

Ce document a été généré automatiquement le 20 octobre 2022.

\section{(c) (†) $\odot$}

Creative Commons - Attribution - Pas d'Utilisation Commerciale - Pas de Modification 4.0 International - CC BY-NC-ND 4.0

https://creativecommons.org/licenses/by-nc-nd/4.0/ 


\section{Antoine Faure, Franck Gaudichaud, María Cosette Godoy H., Fabiola Miranda P., René Jara (dir.), Chili actuel : gouverner et résister dans une société néolibérale}

Paris, L'Harmattan, 2016, 280 p.

Stéphane Boisard

\section{RÉFÉRENCE}

Antoine Faure, Franck Gaudichaud, María Cosette Godoy H., Fabiola Miranda P., René Jara (dir.), Chili actuel : gouverner et résister dans une société néolibérale, Paris, L'Harmattan, 2016, $280 \mathrm{p}$.

1 Cet ouvrage collectif est issu d'un colloque tenu à l'Université de Grenoble-Alpes - sans en être des actes - et entend rendre compte du Chili actuel. Le titre du colloque et de ce livre fait écho au célèbre essai de Tomás Moulian publié en 1997, Chile actual. Anatomía de un mito (Lom, Santiago du Chili). Pour comprendre cette filiation - qui éclaire le titre de l'ouvrage Chili actuel : gouverner et résister dans une société néolibérale -, il convient de revenir brièvement sur l'essai du sociologue chilien, un des plus grands intellectuels de ce pays et Prix national des Sciences sociales et des Humanités en 2015. Il y démystifiait ce Chili, jaguar de l'Amérique latine, encensé par les marchés financiers et élevé au rang de modèle à suivre pour une Europe de l'Est et une Afrique qu'il fallait convertir, à marche forcée, à l'économie de marché financiarisée. Moulian auscultait sans concession cette société de la transition, consumériste et sans mémoire, dont les nouveaux gouvernants démocratiques, réunis au sein de la coalition Concertación de Partidos por la Democracia, cherchaient à effacer l'origine : "En la matriz de una dictadura 
terrorista devenida dictadura constitucional se formó el Chile actual, obsesionado por el olvido de esos orígenes" ["Dans la matrice d'une dictature terroriste devenue dictature constitutionnelle le Chili actuel se forma, obsédé par l'oubli de ses origines »] (Tomás Moulian, 18).

2 Ce livre est composé d'articles qui s'inscrivent dans des sciences humaines et sociales engagées dans les débats citoyens actuels et les conflits en cours. Il est organisée en trois grandes parties: 1/. Résistances collectives au gouvernement néolibéral. 2/. Subjectivités et identités dans le Chili néolibéral. 3/. Transversalisation des logiques de marché dans l'action publique chilienne. Pour dépasser ces parties quelques peu artificielles, nous proposons de revenir aux thématiques du colloque et citer les auteurs qui y ont publié un chapitre : partis politiques (D. Grimaldi); participation citoyenne et questions de genre (G. Carvajal, M. Cosette, G. Hidalgo, F. Miranda); action collective et syndicat (A. Aravena, S. Pérez) ; Mapuche et la question autochtone (B. Sepúlveda); Éducation (C. González) ; politiques de la ville et mobilité (C. Pulgar, Y. Jouffe, A. Lazo et D. Carvajal, A. Montoni) ; ressources naturelles et écologie (D. Inostrosa, G. Cánoves). Sans qu'il soit possible ici de détailler toutes les contributions, notons toutefois que leur lecture offre un horizon large et documenté pour comprendre comment cette logique "néolibérale» a réussi à imprégner de nombreux domaines de la vie économique et sociale. À ce titre, la lecture de ce livre nous invite à penser l'existence au Chili d'une véritable culture utilitariste et individualiste qui imprègne aujourd'hui toutes les relations sociales (entre citoyens au sein d'un espace urbain, entre hommes et femmes, au sein du monde du travail).

Il y a, bien sûr, une contrepartie à ce choix d'offrir un regard pluriel sur la question du néolibéralisme au Chili à partir d'objets d'études variés et déconnectés les uns des autres. En d'autres termes, ce livre a le défaut de sa qualité, celui qui tend finalement à " essentialiser" ce "néolibéralisme " dans une lecture qui assimilerait toutes les pratiques gouvernementales ou celles des acteurs privés à une simple logique de domination ou d'assujettissement des individus contre leur gré. Ce serait, toutefois, faire un procès d'intention fort injuste aux auteurs de ce livre que de supputer qu'ils n'auraient pas réfléchi à cette question sur le plan théorique ou encore historique. Ce serait aussi méconnaître, notamment, la réflexion entamée depuis des lustres par Franck Gaudichaud sur ce sujet ${ }^{1}$. L'introduction de l'ouvrage, écrite à quatre mains avec Antoine Faure, permet de recadrer utilement cette problématique où, de façon œcuménique, le néolibéralisme est envisagé comme "hégémonie », "mode d'accumulation et de production », « art de gouverner », " mais aussi dans les relations de forces locales, nationales et internationales » (p. 11 et 12). Une idée suggérée dans cette introduction pourrait certainement être approfondie, celle de l'existence d'un " néolibéralisme chilien » ou encore d'un " néolibéralisme du Sud », une sorte de " voie chilienne ou latino-américaine au néolibéralisme » qu'il conviendrait d'historiciser. Le retour au pouvoir, ces dernières années, de droites "dures" (Mauricio Macri en Argentine, Jair Bolsonaro au Brésil, Sebastián Piñera au Chili et Iván Duque en Colombie) montrent que celles-ci ne se contentent plus du simple champ économique pour exercer leur hégémonie mais qu'elles ont aussi l'intention de conquérir le pouvoir, sans être forcément très regardantes sur les droits humains ou des principes de la démocratie. Après les «droites gramsciennes du populisme autoritaire » chères à Stuart Hall ${ }^{2}$ qui auraient remporté une victoire idéologique sur « les progressismes » 
dans les années 1980, les droites de cette fin de décennie 2010 ont fait de la conquête du pouvoir politique un critère essentiel de leur action et de la défense de leurs intérêts.

\section{NOTES}

1. On pourra renvoyer ici à son essai Las fisuras del neoliberalismo maduro chileno. Trabajo, "Democracia protegida" y conflictos de clases, http://biblioteca.clacso.edu.ar/clacso/becas/ 20150306041124/EnsayoVF.pdf

2. Stuart Hall, Le Populisme autoritaire. Puissance de la droite et impuissance de la gauche au temps du thatchérisme et du blairisme, Paris, Éditions Amsterdam, 2008.

\section{AUTEURS}

\section{STÉPHANE BOISARD}

Maître de conférences en civilisation latino-américaine. - En poste au Centre universitaire JeanFrançois Champollion, Albi. 